\title{
Is Swaziland on track with the 2015 millennium development goals?
}

\author{
A Sathiya Susuman
}

\begin{abstract}
According to the Millennium Development Goals (MDGs) agreement, each participating country has to periodically provide a report that will show the progress on their achievement towards the goals. This article's aim is to evaluate Swaziland's prospects of achieving eight MDGs by 2015. This article is an analysis of the current situation of Swaziland, and the aim of this analysis is to look beyond the statistical values to see if the achievements (including lifetime achievements) are on track and whether what is yet to be achieved can really be achieved. Secondary information was collected from various sources. Several countries and organizations have committed themselves to the following eight development goals: (1) eradicate extreme poverty; (2) achieve universal primary education; (3) promote gender equality and empower women; (4) reduce child mortality; (5) improve maternal health; (6) combat HIV/AIDS, malaria and other diseases; (7) ensure environmental sustainability; and (8) develop a global partnership for development. National development is dependent on many factors; therefore, different countries across the world have adopted the MDGs as means of alleviating many of the social ills hindering progress and development. Based on different sources, Swaziland is on track with its MDGs, and there is no doubt that Swaziland will continue to work hard to these ends. It has been argued that there has been progress made that has resulted in significant changes to people's lives, but the question that has to be asked is how long these achievements can realistically last. A reduction of the rate of child mortality, maternal mortality and HIV/AIDS in Swaziland are needed.
\end{abstract}

\section{Introduction}

Fifteen years have passed since the establishment of the United Nations' Millennium Development Goals (MDGs). Several countries and organizations have committed themselves to the following eight development goals: (1) eradicate extreme poverty; (2) achieve universal primary education; (3) promote gender equality and empower women; (4) reduce child mortality; (5) improve maternal health; (6) combat HIV/AIDS, malaria and other diseases; (7) ensure environmental sustainability; and (8) develop a global partnership for development (United Nations, 2012). National development is dependent on many factors; therefore, different countries across the world have adopted the MDGs as a means of alleviating many of the social problems that hinder progress and development. For most developing countries, some of these goals are far from being achieved, and this presents 
many challenges with regard to development in most of the countries. Using the available data and studies, this paper aims to evaluate Swaziland's prospects of achieving three of the MDGs by 2015. This paper is based on different findings from different sources, but mainly on statistics on Swaziland in the Millennium Development Goals Report of 2012 (United Nations, 2012). The Kingdom of Swaziland is located in Southern Africa and is landlocked, with the Republic of South Africa and Mozambique forming its borders. In 2000, the Kingdom of Swaziland signed the United Nations Millennium Declaration and, in so doing, embraced the MDGs. Swaziland is guided by the National Development Strategy (NDS) and the Poverty Reduction Strategy and Action Programme (PRSAP), both of which complement the development ideals of the MDGs. Interestingly; the country has developed three consecutive MDGs reports during the years 2003, 2007 and 2010. Swaziland focused on all eight MDGs, but only three goals are likely to be achievable. Therefore, this paper aim is to evaluate Swaziland's prospects of achieving three of the MDGs by 2016. Specifically, these goals are MDG 2: achieve universal primary education (on track); MDG 4: reduce child mortality (on track); and MDG5: improve maternal health (on track).

\section{Methods}

A simple bivariate analysis has been adopted with graphical presentation.

\section{Data}

The data was obtained from various secondary sources, including the Ministry of Economic Planning (Swaziland Millennium Development Goals and Progress Report, 2012), the Swaziland Demographic and Health Survey (SDHS2006-2007) (Central Statistical Office and Macro International Inc., 2008), UNICEF and World Bank data.

\section{Results}

First, we need to discern the first goal. Poverty is a multidimensional phenomenon that is often difficult to define. Due to the complexity of this concept, many developing countries face challenges in terms of targeting poverty and employing strategies to eradicate it. In working toward Goal 1, between 1990 and 2015, Swaziland focused on those people whose income is less than one dollar a day. In this case, Swaziland reduced poverty, but acceleration of the programme is needed to eliminate poverty. Swaziland has made several strides towards eradicating extreme poverty, such as achieving the set targets among the population living below $\$ 1.00$ and $\$ 1.25$ per day (United Nations, 2012; UNICEF et al., 2013). It is important for the country to work within its historical context in trying to alleviate poverty. Furthermore, poverty levels could be drastically reduced by ensuring that there are employment opportunities for youth. Even though Swaziland is unlikely to eradicate unemployment among the different population groups, many developmental strategies have been put in place to ensure that unemployment (and poverty) is eradicated by 2025 .

Regarding Goal 2, the nation strives to ensure that, by 2015, children everywhere, boys and girls alike, will be able to complete a full course of primary schooling. This goal is thus far on 
track and likely to be achieved (World Health Organization, 2012). Currently, however, drop-out rates at both primary and secondary levels are high.

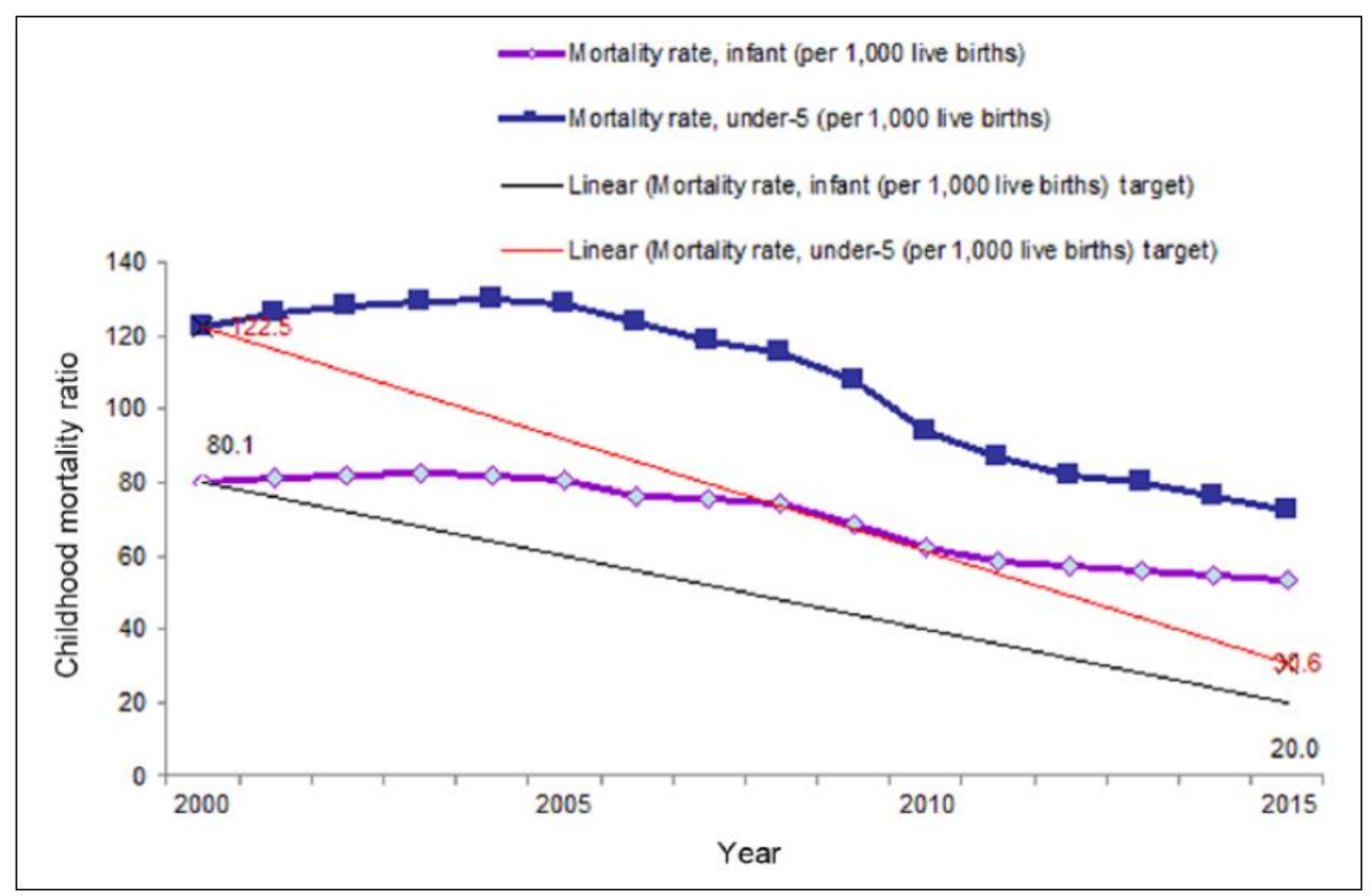

Figure I. Childhood mortality trends in Swaziland.

More than two-thirds of families live in poverty, and many parents struggle to pay school fees and other costs that are often far beyond their means (Tsawe et al., 2015). Moreover, the current situation regarding the matric pass rate (i.e. grade twelve) is another avenue that needs much consideration; measures need to be put in place in order to increase the overall pass rate among students in secondary education.

Goal 3 seeks to eliminate gender disparity in primary and secondary education, preferably by 2015, and in all levels of education no later than 2015 (on track) (World Health Organization, 2010, 2013). Swaziland is a patriarchal society where male dominance has been the norm for hundreds of years. Even though strides have been made to address gender and racial inequalities, there is still much room for improvement and a need for more research on issues of gender and empowerment in the country.

Goal 4 seeks to reduce by two-thirds, between 1990 and 2015, the under-five mortality rate (the present solution needs acceleration and more comparable data is required). Child mortality and under-five mortality rates are declining, and goal 4 is thus far on track, but the statistics are still disturbing when compared with other countries (see Figure 1). Swaziland's maternal health relates to child health in such a way that, when the mother is healthy, the child has better odds of being healthy (Tsawe et al., 2015). Swaziland's maternal antenatal care, delivery care at health institutions and immunization figures are significant 
to this end. Furthermore, in addressing the problems noted in Goal 5 , this goal can also be addressed.

Goal 5 seeks to reduce by three-quarters, between 1990 and 2015, the maternal mortality rate (MMR). After reviewing different sources, Goal 5 is likely to be achieved by 2015, which includes universal access to reproductive healthcare (on track). The three dimensions of maternal health (i.e. antenatal care, delivery care and postnatal care) are important factors that need to be completely addressed in order for the country to progress towards the improvement of overall maternal health. Swaziland's antenatal care and immunization rates are quite high (World Health Organization, 2010, 2012, 2013), but postnatal care still needs improvement. To address the challenges that the country faces regarding maternal and child health, there needs to be more done in terms of awareness through messages that relay the importance of these services.

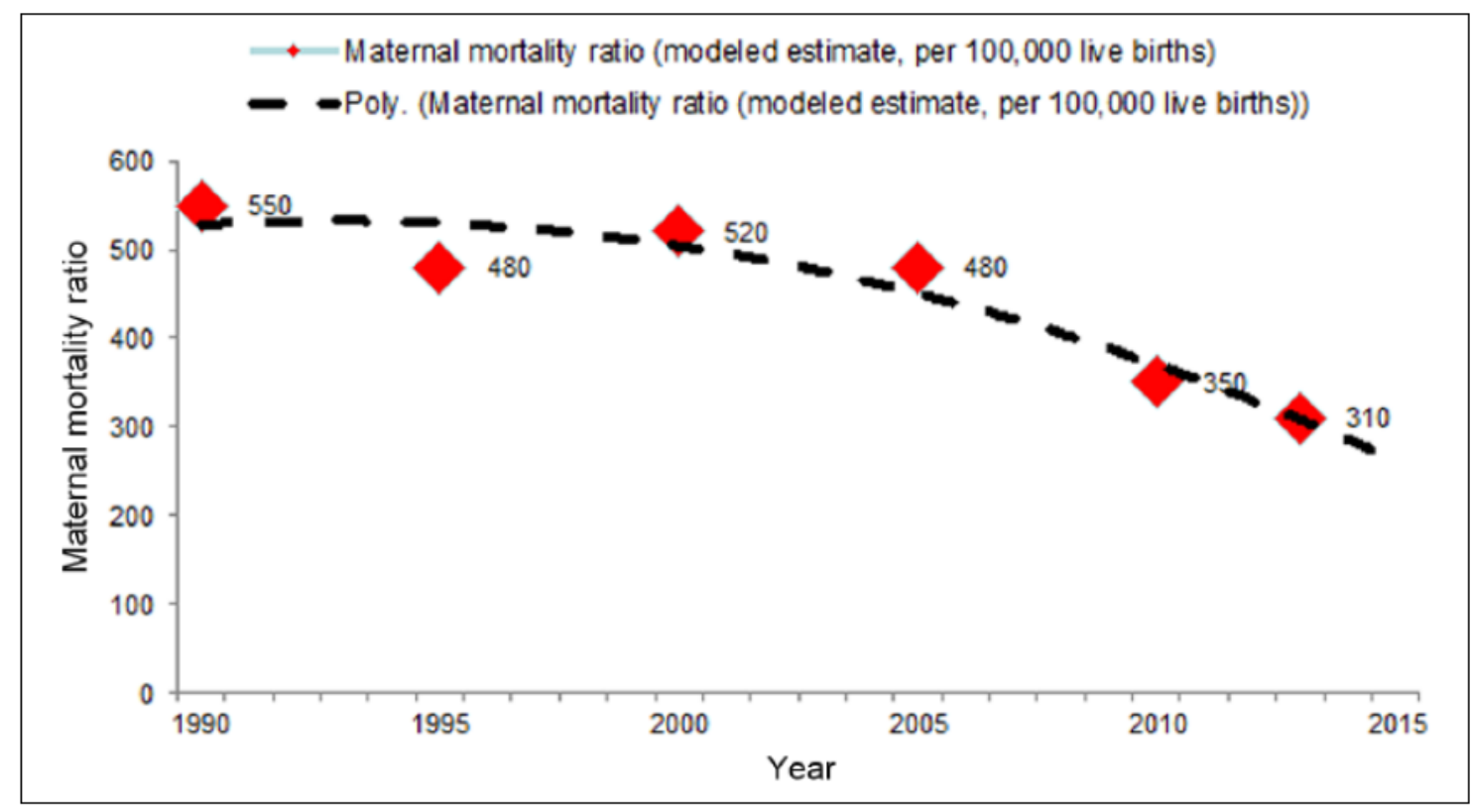

Figure 2. Maternal mortality ratios (estimate per 100,000 live births) in Swaziland.

It might be that many women are not informed about these services and about the dangers of not taking maternal and child health seriously. Education is the most fundamental tool that women should be equipped with to reduce child mortality and improve maternal health (see Figure 2).

Goal 6 says that, by 2015, the spread of HIV/AIDS should be reversed (on track). More specifically, the nation should achieve, by 2015, universal access to treatment for HIV/AIDS for all those who need it (on track). Having halted and begun to reverse the incidence of malaria and other diseases, this goal is on track (likely to be achieved) (Central Statistical Office and Macro International Inc., 2008). However, a study shows that antiretroviral therapy coverage (for the percentage of people living with HIV) in Swaziland has gradually 
increased (see Figure 3). There is no hesitation about saying that Swaziland needs to work hard; there is a very large number of people living with the pandemic (above 60\%), which has shown an increasing trend over the years since the first case of the virus was discovered in the country. Furthermore, as per the country's MDG report, Swaziland is unlikely to reach the MDG target of increasing awareness of HIV/AIDS among youths aged 15- 24 years by 2015; and it is also unlikely that the target rate for condom use will be reached (UNICEF, 2013). This shows the complexities of the pandemic, as HIV/AIDS is influenced by many factors central to people's behaviour and life choices. Another supportive study shows that the prevalence of HIV among females was higher than in males (see Figure 4). Therefore, it is generally a challenge to try and change the way in which people lead their lives. There need to be strategies put in place to promote low-risk sexual behaviours among youths and adults. On a basic level, most people already know about the existence of HIV/AIDS, even though some may think that it will never happen to them. Thus, there is a need to educate people about the tangible dangers of risky sexual behaviours and the ways by which they could limit their risks of acquiring the virus.

Part of Goal 7 is to integrate the principle of sustainable development into the country's policies and programmes, and to reverse the loss of environmental resources (on track). Additionally, the goal is to reduce biodiversity loss and achieve, by 2015, a significant reduction in the rate of loss (acceleration required). To this end, studies show the proportion of people without sustainable access to safe drinking water and sanitation (on track) (World Health Organization, 2010). Swaziland has thus far improved access and provision of basic services over time. A target that has already been reached before the target year (the target being $85 \%$ by 2015) is the percentage of the population using an improved drinking water source (estimated at $85 \%$ in 2013) (World Health Organization, 2012). 


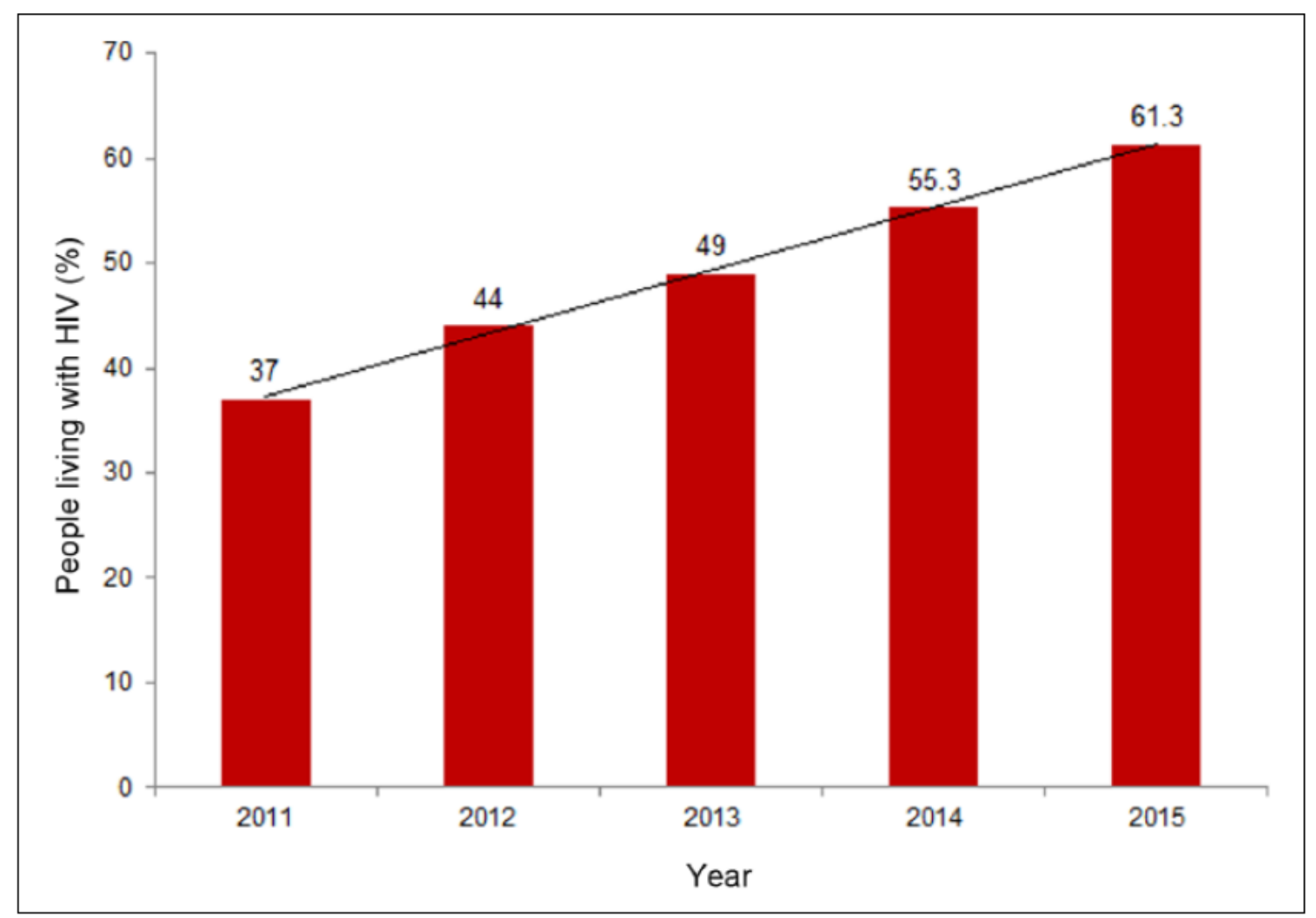

Figure 3. Antiretroviral therapy coverage (percentage of people living with HIV) in Swaziland.

The percentage of the population using improved sanitation facilities has improved over the years since 1990 (estimated at 60\% in 2010), just $8.15 \%$ short of the $74.65 \%$ targeted for 2015 (World Health Organization, 2012). On the other hand, a target that Swaziland is unlikely to reach by 2020 is the percentage of terrestrial areas protected (estimated at $6.71 \%$ of total in 2012) - with an estimated target of $17 \%$ by 2020 (World Health Organization, 2012). This particular fact speaks directly to nature conservation, where the main issue is the protection of the nature reserves and other lands that hold environmental value. Throughout the world, populations have become too dependent on the environment and its resources, which makes environmental sustainability a concept that has (in recent years) taken the global stage. Protecting and preserving the current resources is paramount to ensuring that the country survives and is able to sustain itself.

Lastly, Goal 8 is to further develop an open, rule-based, predictable and nondiscriminatory trading and financial system, while addressing the special needs of the leastdeveloped countries (data is not available for this target). Global partnerships are essential in bridging the gap between rich and poor countries. Generally, there is a wide gap between the developing and the developed world, which presents many challenges for developing countries regarding funding and sustainability of their markets. In 2010, the country achieved its 2015 targets for the debt to gross national income (GNI) ratio (which is meant to stay below 44.4) and that of cellular telephone subscribers per 100 of the population (which is meant to stay at 50 and above). Targets likely to be achieved by 2015 include the percentage 
of investment share in GDP and gross savings as a percentage of gross disposable income (GDI).

\section{Conclusions}

Overall, in signing the Millennium Declaration, Swaziland encompassed the views of the Millennium Development Goals as practical, systematic and time-bound strategies for fighting poverty. The country has made significant strides by reducing the level of poverty incredibly in 2012.

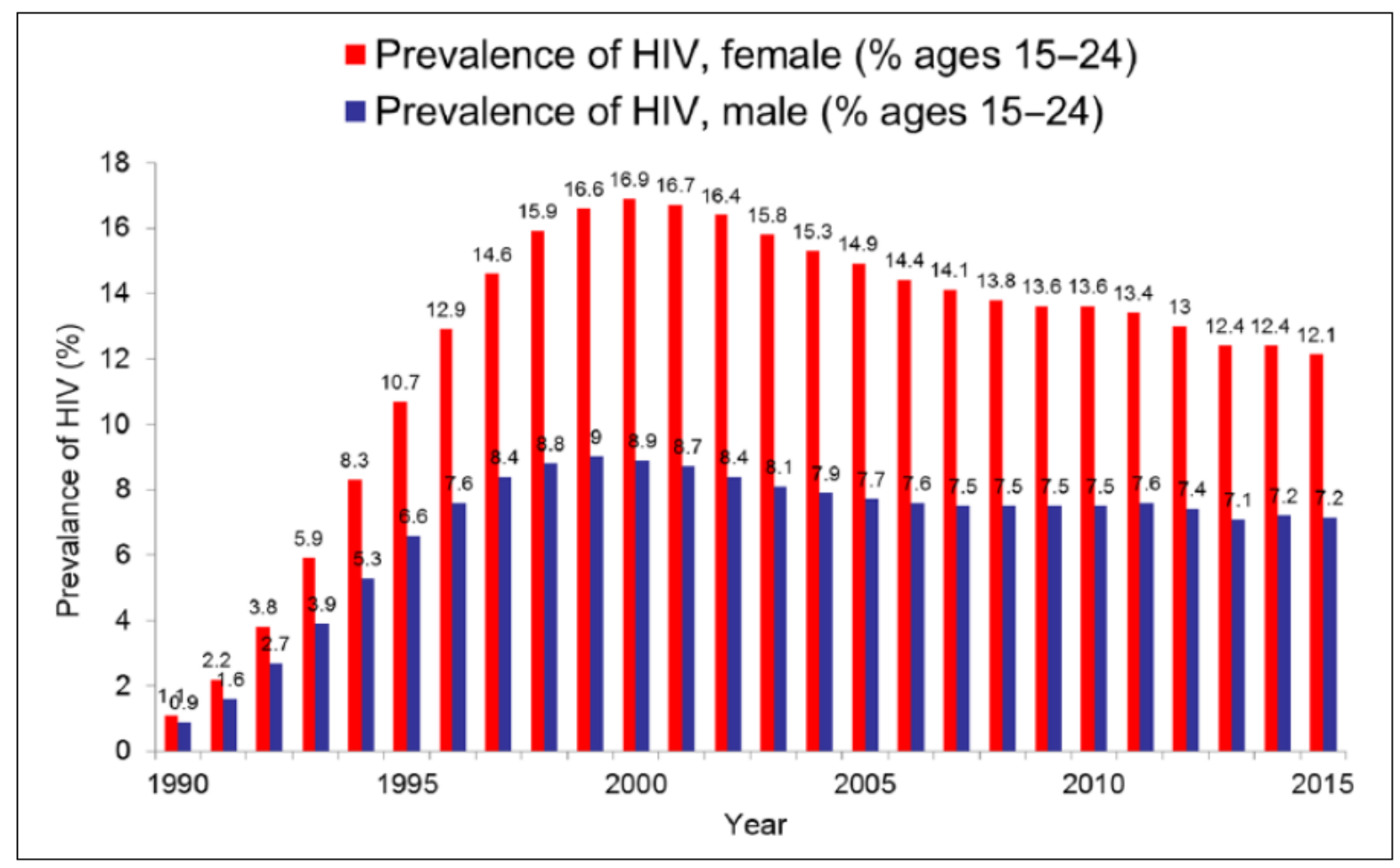

Figure 4. Prevalence of HIV (male and female) in Swaziland.

Because of the country's internal productivity, excessive pressure has been placed on the use of limited domestic resources as well as from external issues like the global financial meltdowns. As the MDG report suggested, there are three goals that are likely to be achievable in Swaziland. Of course, it is possible to achieve more, but Swaziland must primarily work on maternal health care. The MMR is still high, and the prevalence of HIV among females is above $60 \%$. The child and under-five mortality rates show that they are in decline, but the rates are still high. Therefore the studies suggest, in particular, reworking and then implementing educational programmes to educate mothers on the importance of maternal (postnatal) and child healthcare services. This will then give women and their families more knowledge about the importance of these services. Even though the utilization of antenatal, delivery and immunization services is quite high, there is room for improvement to achieve MDGs 4 and 5. Similarly, in regard to disease, prevention is better than any cure, and 
therefore condom use should be promoted in the target populations, especially the youth, to eradicate HIV and AIDS.

\section{Declaration of Conflicting Interests}

The author(s) declared no potential conflicts of interest with respect to the research, authorship, and/or publication of this article.

\section{Funding}

The author(s) received no financial support for the research, authorship, and/or publication of this article. 


\section{References}

Central Statistical Office and Macro International Inc. (2008). Swaziland Demographic and Health Survey 2006-07. Mbabane, Swaziland: Central Statistical Office and Macro International Inc.

Swaziland Millennium Development Goals and Progress Report. (2012). Improving The Lives of the Present and Future Generations. Ministry Of Economic Planning And Development, Swaziland Government, pp. 1-156.

Tsawe M, Moto A, Netshivhera T, et al. (2015) Factors influencing the use of maternal healthcare services and childhood immunization in Swaziland. International Journal for Equity in Health 14(1): 32.

UNICEF (2012) UNICEF Anuual Report 2012, pp. 1-42, ISBN:978-92-806-4693-1.

UNICEF (2013) UNICEF Anuual Report 2013, pp. 1-48, ISBN:978-92-806-4755-6.

United Nations (2012) The Millennium development Goals Report 2012, We Can End Poverty 2015 Millennium Development Goals. New York: United Nations, pp 1-72.

United Nations (2012) The Millennium Development Goals Report. New York: United Nations.

World Health Organization (2010) Swaziland: Factsheets of Health Statistics. Geneva: WHO Regional Office for Africa.

World Health Organization (2013) World Malaria Report. Geneva: WHO.

World Health Organization, UNICEF, UNFPA and The World Bank (2012) Trends in Maternal Mortality: 1990 to 2010. WHO, UNICEF, UNFPA and The World Bank Estimates. Geneva: World Health Organization Press.

\section{Author biography}

A Sathiya Susuman is associate professor at the Faculty of Natural Sciences, Department of Statistics and Population Studies, University of the Western Cape, South Africa. His research interests include technical demography, fertility, mortality, gender, reproductive health, vulnerable diseases, HIV/AIDS, health policy and public health. He has published several international accredited journal articles in BMC Reproductive Health, BMC Research Note, the International Journal of Equity in Health, the Journal of Public Health, SAHARA J: Journal of Social Aspects of HIV/AIDS Research Alliance, the Journal of Social Science Research, the Journal of Asian and African Studies, Plos One, Clinical Case Report, the Iranian Journal of Public Health and in other journals and edited volumes. 